\title{
The effect of energy intake during rearing on reproductive traits in gilts
}

\author{
L. A. den Hartog
}

Department of Animal Nutrition, Agricultural University, Haagsteeg 4, 6708 PM Wageningen, Netherlands

Received 4 April 1984; accepted 10 November 1984

Key-words: energy intake, gilt, litter size, birth weight, feeding, oestrus, conception rate.

\section{Summary}

The effect of level of energy intake from 12 until 38 weeks of age on reproductive performance in Dutch Landrace gilts was studied. Four treatments based on different energy levels (about $3.0 \mathrm{M}, 2.5 \mathrm{M}, 2.1 \mathrm{M}$ and $1.8 \mathrm{M} ; \mathrm{M}=$ metabolizable energy required for maintenance) were tested. All animals received a similar daily amount of protein per $\mathrm{kg}$ body weight. A total of 538 gilts were inseminated. Conception rate was lower for gilts (67 and $64 \%)$ at the two higher levels of energy intake than for gilts at the two lower levels (both $76 \%$ ). A significant interaction for ovulation rate was found between energy intake and oestrus number at the average age of 8.5 months.

The number of piglets born alive, the average birth weight and the homogeneity of the litter (measured as standard deviation of birth weights within a litter) were not clearly affected by energy intake. The pooled regression coefficients of average birth weight on weight of the sow on the day before farrowing and rate of gain during the last 100 days of pregnancy were significant $\left(2.68 \mathrm{~g} \mathrm{~kg}^{-1}\right.$ and $5.45 \mathrm{k} \mathrm{kg}^{-1}$, both $P<0.01)$. The effect of induction of gilts with PG600 on the ovulation rate seemed to be dependent on the weight or fatness of the gilts $(14.1,14.7,21.0$ and 18.8 respectively).

\section{Introduction}

An increase in energy supply to gilts during the rearing period will result in higher weight, more backfat and younger age at puberty (den Hartog \& Noordewier, 1984). The level of feeding during rearing may also affect later reproductive performance. For example, a high energy intake results in an increased ovulation rate in gilts (reviews by Anderson \& Melampy, 1972 and den Hartog \& van Kempen, 1980). An increased ovulation rate will not always result in more piglets born alive (Brooks \& Cole, 1974). Therefore, part of the pregnant gilts in the experiment de- 
scribed by den Hartog \& Noordewier (1984) were slaughtered and the rate of ovulation and number of foetuses were determined. The effects of energy intake and weight of the sow on litter size, birth weight of the piglets and homogeneity of the litter at farrowing were studied in another part of the pregnant gilts. Since gilts needed to farrow within a relative short time it was decided to inseminate at a similar chronological age. Therefore, the oestrus number at insemination may not be similar for all gilts (see den Hartog \& Noordewier, 1984).

Gilts mated at first oestrus produced a smaller litter than gilts mated at a third oestrus as shown in studies by Pay \& Davies (1973), MacPherson et al. (1977) and Young \& King (1981). Gilts mated at first oestrus in these studies were younger than gilts mated at their third oestrus. Consequently, their chronological age was confounded with sexual age. Gilts mated at a second oestrus with an average age of 198 days had 0.9 piglets less in the first litter than gilts mated at a second oestrus with an average age of 237 days (Brooks \& Smith, 1980). The difference in age at puberty was obtained by the presence or absence of a boar. Van der Steen (1983) found an increased litter size in gilts inseminated at a second or later oestrus than for gilts inseminated at a first oestrus of similar chronological age. Therefore it can be concluded that in this study in which the effect of energy intake during rearing on litter traits is investigated, the oestrus number at conception needs to be taken into account.

\section{Material and methods}

680 Gilts of the Dutch Landrace, from 12 to 38 weeks of age, were assigned to one of four energy levels. The study was carried out with 9 consecutive batches, each with 64 to 80 animals. The feeding strategy was based on differences in energy supply for production (treatments $1,2,3$ and 4 were aimed at $3 \mathrm{M}, 2.5 \mathrm{M}, 2.1 \mathrm{M}$ and 1.8 M; $\mathbf{M}=$ metabolizable energy required for maintenance) with a similar protein supply, according to a model given by den Hartog \& Verstegen (1984). More details on the rearing of the gilts are given by den Hartog \& Noordewier (1984).

Insemination took place within a period of 6 weeks after the gilts reached 35 weeks of age. Gilts which did not show oestrus before 38 weeks of age were injected intramuscularly with $400 \mathrm{IU}$ of pregnant mare serum and $200 \mathrm{IU}$ of human chorion gonadotrophin (PG600; Intervet, Boxmeer, Netherlands) at 38 weeks of age. Gilts were housed in groups of four during pregnancy. Ambient temperature was maintained at a minimum of $17^{\circ} \mathrm{C}$. The light/dark regime provided light from $08 \mathrm{~h} 00$ to $20 \mathrm{~h} 00$ and darkness from $20 \mathrm{~h} 00$ to $08 \mathrm{~h} 00$. After 38 weeks of age all gilts received $2.5 \mathrm{~kg}$ of feed per day until slaughter or farrowing. The composition of the diet was similar to that described by den Hartog \& van der Steen (1981). The gilts were fed twice daily. Water was always available from a nipple drinker. Of the 382 and 45 gilts that were pregnant after the first and second insemination respectively, 290 were kept to produce their first litter. Corpora lutea and number of foetuses were counted after slaughtering in 224 and 79 sows, respectively; 58 pregnant sows were used for other experiments. On the average, gilts were slaughtered at day $49( \pm 18)$ of pregnancy. Gilts chosen for slaughter were comparable to gilts that completed 
their pregnancy because their weight and backfat thickness at the end of the rearing period (38 weeks of age) and age at spontaneous first oestrus were similar.

\section{Measured and calculated traits}

When possible the following traits were determined:

- oestrus number at conception

- induced or spontaneous oestrus

- number of corpora lutea (ovulation rate)

- number of foetuses

- embryonic survival ((number of foetuses: number of corpora lutea) $\times 100)$

- number of piglets born (dead or alive)

- weight prior to $(<24 \mathrm{~h})$ parturition of the gilts

- weight after $(<24 \mathrm{~h})$ parturition of the gilts

- backfat thickness and heart girth prior to parturition

- birth weight per litter (average per piglet)

- standard deviation of birth weights within a litter (homogeneity parameter)

\section{Statistical analysis}

Data were analysed by least squares analysis (Nie et al., 1975). Preliminary calculations showed that there were no significant differences in reproductive traits between animals in various batches. Production traits were analysed with treatment and batch as factors while the reproductive traits were analysed with treatment and oestrus number at conception (CO =1,2, 3 is first, second and third or fourth; 4 is induced first oestrus, respectively) as factors. Reproductive traits depend on oestrus number at conception. Energy intake was the factor of interest. Therefore, these factors are simultaneously included in the models in all analyses of reproductive traits. With the exception of ovulation rate preliminary calculations indicated no significant interactions between batch and treatment factors and between treatment and the $\mathrm{CO}$ factor. Therefore, the non significant interactions were excluded from further analyses. The effects of age at insemination, weight at farrowing and rate of gain during pregnancy on litter size and birth weight were calculated in the sows with spontaneous oestrus by aid of the following model:

$Y_{i j k}=\mu+\mathrm{T}_{i}+\mathrm{CO}_{j}+b_{1} X_{i j k}+b_{2} Z_{i j k}+e_{i j k}$

in which

$Y_{i j k}=$ average birth weight, standard deviation of birth weight, total number of piglets born or number of piglets born alive

$\mu \quad=$ mean

$\mathrm{T}_{i}=$ treatment $(i=1,2,3,4)$

$\mathrm{CO}_{j}=$ oestrus number at conception $(\mathrm{j}=1,2,3,4)$

$X_{i j k}=$ age at insemination or weight measured within a day before farrowing or rate of gain during last 100 days of pregnancy

$Z_{i j k}=$ total number of piglets born

$b_{1}, b_{2}=$ regression coefficients 


\section{A. DEN HARTOG}

$e_{i j k}=$ error

If $Y_{i j k}$ was total number of piglets born or number of piglets born alive the covariable $Z_{i j k}$ was not included in the model.

\section{Results}

A total of 428 gilts was inseminated once after spontaneous oestrus and 110 gilts after induced oestrus (Table 1). 305 (71\%) and $77(70 \%)$ gilts, respectively, were pregnant after the first insemination. After the second insemination 36 from the 75 gilts with a spontaneous oestrus $(48 \%)$ were pregnant. These numbers were 9 out of $13(69 \%)$ for the induced gilts. The number of gilts inseminated at a spontaneous oestrus and at an induced oestrus which were kept to produce a litter were 244 and 46 gilts, respectively (at random selection from gilts which became pregnant after first insemination). 175 Gilts with spontaneous oestrus and 49 gilts with induced oestrus were slaughtered in order to determine the ovulation rate. The remainder was used for other experiments. Because litter characteristics (performance) did not differ significantly between gilts pregnant after first or second insemination, these data of the two groups were combined.

Gilts inseminated at a spontaneous oestrus, which became pregnant, had a higher weight at an average age of 38 weeks and had more backfat at an average age of 187 days than gilts which did not conceive at first insemination (weight 144 and 138 $\mathrm{kg}, P<0.01$ and backfat thickness 11.6 and $10.8 \mathrm{~mm}, P<0.05$, respectively).

\section{Effect of level of energy intake during rearing on production traits}

The effect of the level of energy intake on production traits, which were found to be significant at 38 weeks of age, were also found to be significant at farrowing (Table 2). Gilts with a reduced energy intake during the rearing period had a lower weight and a smaller heart girth and less backfat at farrowing $(P<0.01)$. Gilts with a high energy intake during rearing lost more weight than gilts with a low energy intake as a result of farrowing $(P<0.01)$, (see Table 2$)$. Production traits were cor-

Table 1. The number of gilts inseminated at a spontaneous or induced oestrus and number of gilts which produced a litter.

$\begin{array}{llll}\text { Treatment } & & & \text { Total } \\ 1 & 2 & 3 & 4\end{array}$

Sows with a spontaneous oestrus inseminated

pregnant after first insemination farrowed

$\begin{array}{rrrrr}100 & 107 & 114 & 107 & 428 \\ 66 & 69 & 87 & 83 & 305 \\ 57 & 55 & 68 & 64 & 244\end{array}$

Sows with an induced oestrus inseminated pregnant after first insemination farrowed

$\begin{array}{rrrrr}22 & 21 & 33 & 34 & 110 \\ 16 & 13 & 24 & 24 & 77 \\ 8 & 6 & 18 & 14 & 46\end{array}$


Table 2. Production traits of the sows during pregnancy and at farrowing for the four treatment groups.

\begin{tabular}{|c|c|c|c|c|c|}
\hline & \multicolumn{4}{|c|}{ Treatment } & \multirow[t]{2}{*}{$\mathrm{CV}^{1}$} \\
\hline & 1 & 2 & 3 & 4 & \\
\hline Weight before farrowing ${ }^{2}(\mathrm{~kg})$ & 219 & 210 & 194 & 184 & 8.2 \\
\hline Weight after farrowing $2(\mathrm{~kg})$ & 197 & 191 & 177 & 167 & 8.3 \\
\hline Backfat thickness at farrowing $2(\mathrm{~mm})$ & 26.4 & 25.0 & 22.0 & 18.7 & 17.2 \\
\hline Heart girth at farrowing $2(\mathrm{~cm})$ & 132.5 & 129.3 & 124.7 & 120.9 & 4.1 \\
\hline Rate of gain during the last 100 days of pregnancy $(\mathrm{kg})$ & 55.6 & 58.1 & 58.4 & 62.8 & 14.6 \\
\hline
\end{tabular}

${ }_{1}$ Coefficient of variation calculated as (residual standard deviation/mean) $\times 100$.

${ }^{2}$ Probability of treatment and batch $(P<0.01)$.

rected for significant batch effects $(P<0.01)$. Rate of gain was increased during the last 100 days of pregnancy in gilts with a reduced energy intake during rearing.

\section{Effect of level of energy intake during rearing on reproductive traits}

The reproductive traits of sows with spontaneous oestrus for the different treatment groups are presented in Table 3. Gilts with a high level of energy intake (Treatments 1 and 2) had a lower conception rate after first insemination (67 and $64 \%$ ) than gilts with a low energy intake (Treatments 3 and $4 ; 76$ and $76 \%$, respectively, Table 3 ). Differences in conception rate were not significant after the second insemination between gilts of the four treatment groups. Because ovulation rate did not differ significantly between the pregnant and non pregnant gilts which were slaughtered, these two groups were combined. There was a significant interaction between treatment and oestrus number at conception for ovulation rate $(P<$ 0.05 ). Gilts with a high energy intake (Treatment 1 ) had a higher ovulation rate as the oestrus number increased. Gilts with a low energy intake (Treatment 4) had a similar ovulation rate at different oestrus numbers (see Table 4). Number of foetuses and embryonic survival were not affected by energy intake during rearing. Total numbers of piglets born tended to be higher for gilts with higher energy intake during rearing (see Table 3 ). Number of piglets born alive per litter did not differ significantly among the four treatment groups. Average birth weight and the standard deviation of birth weights within a litter were not affected by energy intake during rearing.

The results of the regression of litter characteristics on sow data are presented in Table 5. An increase in litter size with 1 piglet resulted in a 26-g decrease in average birth weight $(P<0.01)$ and an increased standard deviation of birth weight within a litter of $3.4 \mathrm{~g}(P<0.10)$ respectively. The correlation coefficient between birth weight and litter size was $-0.33(P<0.01)$ and $0.15(P<0.02)$ between birth weight and standard deviation of birth weight.

Age at insemination or weight at farrowing was not related to litter size. Gilts with a heavier weight at farrowing produced heavier piglets $(P<0.01)$ but had also a greater variation in birth weight of piglets within a litter $(P<0.10)$ than gilts with a lower weight at farrowing.

The mean age at insemination was $257 \pm 7$ days. Gilts which were older at the 


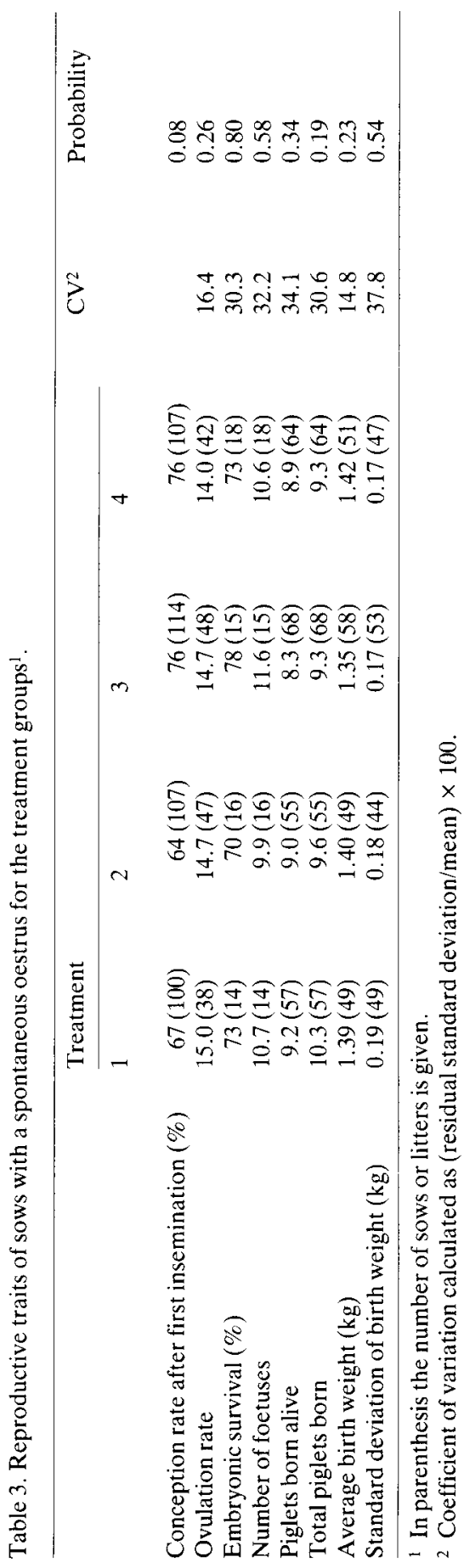


Table 4. Ovulation rate and total numbers of piglets born for gilts of the four treatment groups with a conception at a different oestrus number $(\mathrm{CO})$.

\begin{tabular}{|c|c|c|c|c|}
\hline & \multicolumn{4}{|c|}{ Treatment } \\
\hline & 1 & 2 & 3 & 4 \\
\hline \multicolumn{5}{|c|}{ Ovulation rate ${ }^{I}$} \\
\hline $\mathrm{CO} 1$ & $13.6(7)$ & $14.1(10)$ & $13.4(8)$ & $14.0(9)$ \\
\hline 2 & $14.1(12)$ & $15.4(15)$ & $14.1(21)$ & $14.3(14)$ \\
\hline 3 & $16.2(19)$ & $14.6(22)$ & $15.8(19)$ & $13.7(19)$ \\
\hline \multicolumn{5}{|c|}{ Total number of piglets born ${ }^{l}$} \\
\hline $\mathrm{CO} 1$ & $9.9(17)$ & $9.7(18)$ & $9.8(19)$ & $9.3(33)$ \\
\hline 2 & $10.7(27)$ & $9.9(18)$ & $9.7(36)$ & $9.3(26)$ \\
\hline 3 & $10.2(13)$ & $8.8(19)$ & $7.8(13)$ & $10.6(5)$ \\
\hline
\end{tabular}

1 In parenthesis the number of gilts is given.

time of insemination produced litters with a greater standard deviation in birth weights $(P<0.10)$. Rate of gain during pregnancy was positively related to litter size but had no effect on the uniformity of the litter (see Table 5). Rate of gain during the last 100 days of pregnancy was positively related to average birth weight (pooled coefficient of regression of birth weight corrected for litter size by covariance analysis, on rate of gain was $5.45 \mathrm{~g} \mathrm{~kg}^{-1}, P<0.01$ ).

\section{Effect of oestrus number at conception and induction on reproductive traits}

Gilts inseminated at a first or second spontaneous oestrus had higher conception rates than gilts inseminated at an induced oestrus or at a third or fourth spontaneous oestrus $(P<0.10$, Table 6$)$. Ovulation rate increased at a higher oestrus number, while at an induced oestrus the highest values were found $(P<0.01)$.

The ovulation rate in gilts with a first or second oestrus at the age of 8 months was not clearly affected by energy intake (see Table 4). Gilts at the highest levels of energy intake during rearing had a higher ovulation rate at third or fourth oestrus than gilts at the lowest level of energy intake (Treatment 1 - Treatment $4=2.5$ ova). The ovulation rate in gilts induced in Treatments $1,2,3$ and 4 were $14.1,14.7,21.0$ and 18.8, respectively. Embryonic survival was decreased in gilts mated at their first oestrus compared to gilts mated at a second or higher oestrus number. Gilts that were induced had a lower embryonic survival $(50 \%)$ than gilts mated at a spontaneous first oestrus $(67 \%)$. The number of fetuses was highest in filts inseminated at the third oestrus or higher, while the gilts inseminated at a spontaneous or induced first oestrus had the lowest values (see Table 6). The litter size or number of piglets born alive was similar for the gilts inseminated at a different oestrus number and induced oestrus.

The average birth weight of piglets born from gilts with an induced oestrus was about 110 g lower compared to gilts with a spontaneous oestrus. The litters of gilts with induced oestrus were less homogeneous. The standard deviation of birth 


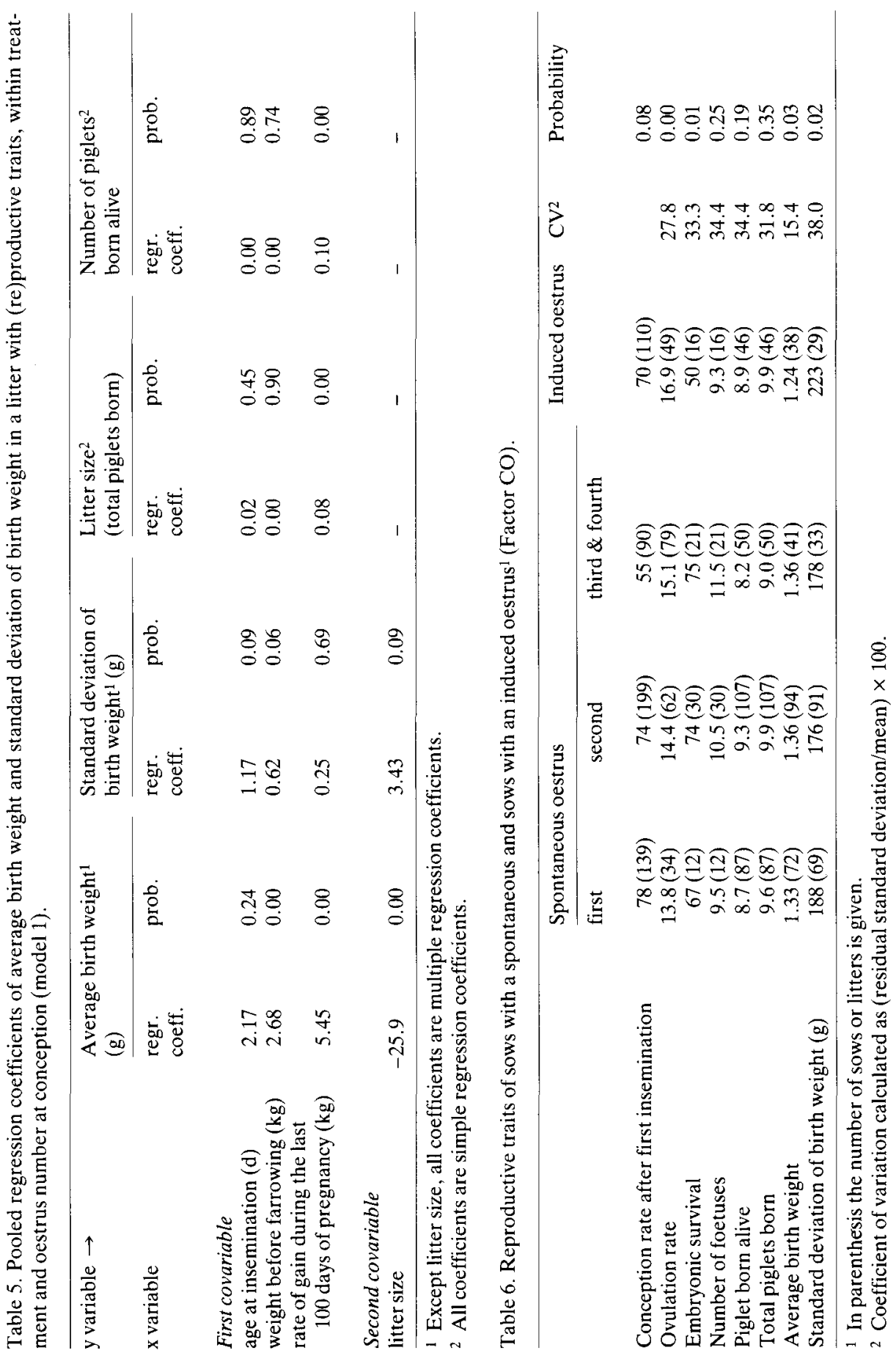


weight within a litter from induced gilts was about $42 \mathrm{~g}$ higher than from gilts with a spontaneous oestrus.

\section{Discussion}

\section{Production traits}

The increase in energy supply to gilts during the rearing resulted in a higher weight at first oestrus (den Hartog and Noordewier, 1984). Heavy animals have an increased energy requirement for maintenance compared to animals with lower body weights kept under similar conditions (ARC, 1981). Therefore, gilts with a higher level of energy intake have less energy available for production during pregnancy than gilts with a lower energy intake during rearing, as all gilts received $2.5 \mathrm{~kg}$ of feed per day during pregnancy. Therefore it is logical that rate of gain during the last 100 days of pregnancy was decreased when energy intake during rearing was high. Differences between production traits at farrowing among the four treatment groups, however, were still significant $(P<0.01$, see Table 2$)$. That indicates that gilts with a slower rate of maternal maturity (due to feed restriction in the rearing period) do not compensate during their first pregnancy.

The weight loss at farrowing was dependent on the weight of the gilts. Gilts with a higher weight (Treatment 1) lost $20.5 \mathrm{~kg}$. Gilts of treatments 2,3 and 4 lost 19.3 , 18.6 and $17.8 \mathrm{~kg}$, respectively. If losses were corrected by substracting the weight of the piglets, which was not significantly different between treatments, the losses were $8.4,8.0,7.1$ and $5.9 \mathrm{~kg}$, respectively. Thus animals with an increased energy intake during rearing showed greater losses of allantoic and amnionic fluids and/or release of maternal water.

\section{Reproductive traits}

Following statistical analysis of data reported in the literature, den Hartog \& van Kempen (1980) also found a rather small difference in conception rate of gilts fed at high and low levels ( 80.5 and $82.6 \%$ respectively). The conception rate after first insemination agrees with that found by van der Steen (1983) in a study with 409 Dutch Landrace gilts $(71 \%)$. A high level of energy intake (2.5 M or more) for gilts during rearing seems to be detrimental for the conception rate.

Gilts with a higher chronological age and inseminated at their third oestrus had a higher conception rate than younger gilts inseminated at the first oestrus (Pay \& Davies, 1973; MacPherson et al., 1977; Young \& King, 1981). It can be concluded from the present experiment and from data of van der Steen (1983) that with the increase of sexual age (oestrus number), but at the same chronological age, the conception rate after first insemination decreases.

Flushing for a period of less than 3 weeks after a period of restricted feed intake resulted in an increased ovulation rate (reviews of Anderson \& Melampy, 1972; den Hartog, 1980). A high feed intake for a longer period also seemed to stimulate ovulation rate (den Hartog \& van Kempen, 1980). Increased ovulation rate will only result in more piglets when the 'maternal limitation' is not reached (Brooks \& Cole, 1974). Since the number of piglets born was similar for all CO groups 
(Table 6) it can be stated that embryonic death was higher in gilts with a high oestrus number at an age of approximately 8.5 months. However the data of the slaughtered gilts and gilts which produced a litter did not agree (Table 6). When the number of fetuses is assumed to be equal to total number of piglets born, the total number of 'piglets' born for sows in the Treatments $1,2,3$ and 4 was 10.4, 9.7, 9.7 and 9.6, respectively. It can be concluded that there is a tendency for gilts with an increased energy intake during rearing to produce more piglets in the first litter. Hovell et al. (1977) and MacPherson et al. (1977) also found an increased litter size when the level of feed intake was high during rearing. The combined data of the classes 1,2 and 3 of the factor $\mathrm{CO}$ were 9.6, 10.0 and 9.7 'piglets', respectively. These results suggest that a second oestrus at a medium age of approximately 8.5 months is most favourable for a high litter size. Van der Steen (1983) also found a smaller litter size in gilts inseminated at the first oestrus than in gilts of the same chronological age but with a higher sexual age.

Friend (1976) found a positive relationship between the weight of a gilt and the weight of its reproductive organs. In the present experiment, however, the litter size and embryonic survival were not significantly affected by energy intake during rearing. The pooled regression coefficient of litter size on weight at farrowing of the gilt was zero. The relationship between weight of the uterus and uterus capacity is not clear and needs to be investigated further. The effect of feeding level during pregnancy on birth weight of the piglets, reported in the literature, is not clear. Some reports mention a higher birth weight of piglets after intakes of metabolizable energy per sow per day above 18 to 25 MJ (Buitrago et al., 1970; Henry \& Etienne, 1978; Walker, 1983). Other reports, however, did not show such effects (Lodge, 1969; Atinmo et al., 1974; Libal \& Wahlstrom, 1977). According to Close et al. (1984) there is a minimum level of nutrient supply which must be provided by the maternal diet and/or by the body reserves to ensure normal foetal growth. In the present experiment gilts with a reduced weight had more energy available for production, while gilts with a higher weight during pregnancy had more body reserves. The minimum level of energy required during pregnancy, as suggested by Close et al. (1984) was probably supplied in all cases. The pooled regression coefficients showed, however, that within the treatment groups rate of gain during pregnancy and weight at farrowing were positively related with average birth weight of the piglets.

The different relation between weight gain during the last 100 days of pregnancy and the number of piglets born between (1) and within (2) treatments can be explained as follows:

- in the first case (1), the rate of gian will be more maternal growth, since the gilts of treatment 4 were not as developed as those of Treatment 1 at conception;

- in the second case (2), rate of gain will be more related to growth of the reproductive organs, including the foetuses.

Gilts with an increased litter size had a higher rate of gain during the last 100 days of pregnancy $(0.88 \mathrm{~kg} /$ piglet, $P<0.01)$. Weight one day prior to farrowing was then also increased $(1.04 \mathrm{~kg} /$ piglet, $P<0.02)$. Van der Steen (1983) also reported that gilts which carried larger litters gained more weight during pregnancy. 


\section{Oestrus induction}

Induction of oestrus with PG600 in pigs resulted in an increased ovulation rate (den Hartog \& van der Steen, 1981; Paterson, 1982). A higher embryonic mortality in the induced sows was also found in the present experiment. A complication in the present experiment was that the insemination of the gilts with an oestrus after induction occurred after the change of feeding level. The effect of induction on reaching oestrus (den Hartog \& Noordewier, 1984) and on ovulation rate seemed to be dependent on the weight or fatness of the gilts since the number of gilts in oestrus and ovulation rate was higher for gilts on Treatments 3 and 4 . The litter size, however, was not increased. Average birth weight and the homogeneity of the litter were lower in induced sows than in sows with a spontaneous oestrus $(P<0.05)$. Gommers et al. (1974) also found a lower average birth weight of piglets from induced gilts $(1.24$ and $1.45 \mathrm{~kg})$. The number of piglets born alive, however, increased (8.7 and 7.7) compared with gilts mated at a spontaneous oestrus.

\section{References}

Anderson, L. L. \& R. M. Melampy, 1972. Factors affecting ovulation rate in the pig. In: D. J. A. Cole (Ed.), Pig production. Butterworths, London, p. 329-366.

A.R.C., 1981. The nutrient requirements of pigs. Commonwealth Agricultural Bureaux, Slough, U.K., $307 \mathrm{pp}$.

Atinmo, T., W. G. Pond \& R. H. Barnes, 1974. Effect of maternal energy vs. protein restriction on growth and development of progeny in swine. Journal of Animal Science 39: 703-711.

Brooks, P. H. \& D. J. A. Cole, 1974. The effect of nutrition during the growing period and the oestrus cycle on the reproductive performance of the pig. Livestock Production Science 1: 7-20.

Brooks, P. H. \& D. A. Smith, 1980. The effect of mating age on the reproductive performance, food utilisation and liveweight change of the female pig. Livestock Production Science 7: 67-78.

Buitrago, J., J. H. Maner \& J. T. Gallo, 1970. Effect of gestation energy level and reproductive performance. Journal of Animal Science 31: 197 (abstr.)

Close, W. H., J. Noblet \& R. P. Heavens, 1984. The partition of body-weight gain in the pregnant sow Livestock Production Science (in press).

Friend, D. W., 1976. Nutritional effects on age at puberty and plasma amino acid level in Yorkshire gilts and on chemical composition, nucleic acid, fatty acid and hydroxyproline contents of the uterus. Journal of Animal Science 43: 404-412.

Gommers, Th. A., A. Mulder \& J. H. A. te Brake, 1974. Ervaringen met het hormoonpreparaat PG600 bij varkens. Rapport C-235, I.V.O. 'Schoonoord', Zeist, 7 pp

Hartog, L. A. den, 1980. De relatie voeding-vruchtbaarheid bij (opfok)zeugen. Dept. of Animal Nutrition, Agricultural University, Wageningen, 55 pp.

Hartog, L. A. den \& G. J. M. van Kempen, 1980. Relation between nutrition and fertility in pigs. Netherlands Journal of Agricultural Science 28: 211-227.

Hartog, L. A. den \& G. J. Noordewier, 1984. The effect of energy intake on age at puberty in gilts. Netherlands Journal of Agricultural Science 32: 000-000.

Hartog, L. A. den \& H. A. M. van der Steen, 1981. Reproductive traits in primiparous sows in relation to feeding level. Netherlands Journal of Agricultural Science 29: 285-296.

Hartog, L. A. den \& M. W. A. Verstegen, 1984. The effect of energy intake of gilts on the supply of metabolizable energy and protein deposition. Netherlands Journal of Agricultural Science 32: 87-99.

Henry, Y. \& M. Etienne, 1978. Alimentation energetique du porc. Journées de Recherche Porcine en France 10: 119-165.

Hovell, F. D., R. M. MacPherson, R. M. J. Crofts \& K. Pennie, 1977. The effect of energy intake and mating weight on growth, carcass yield and litter size of female pigs. Animal Production 25: 233-245.

Netherlands Journal of Agricultural Science 32 (1984) 
Libal, G. W. \& R. C. Wahlstrom, 1977. Effects of gestation energy levels on sow productivity. Journal of Animal Science 45: 286-292.

Lodge, G. A., 1969. The effects of pattern of feed distribution during the reproductive cycle on the performance of sows. Animal Production 11: 133-143.

MacPherson, R. M., F. D. Hovell \& A. S. Jones, 1977. Performance of sows first mated at puberty or second or third oestrus, and carcass assessment of oncebred gilts. Animal Production 24: 333-342.

Nie, N. J., C. H. Hull, J. C. Jenhuis, K. Steinbrenner \& D. H. Brent, 1975. Statistical package for the social sciences, 2nd ed. McGraw-Hill, New York.

Paterson, A. M., 1982. The controlled induction of puberty in the gilt using boar stimulation and exogenous hormones. Contribution to the Intervet seminair: Control of oestrus cycle in the pig.

Pay, M. G. \& T. E. Davies, 1973. Growth, food consumption and litter production of female pigs mated at puberty and at low body weights. Animal Production 17: 85-91.

Steen, H. A. M. van der, 1983. Maternal and genetic influences on production and reproduction traits in pigs. Doctoral thesis, Agricultural University, Wageningen, $112 \mathrm{pp}$.

Walker, N., 1983. The effects of food intake in gestation on sows lactating for 14 days. Animal Production 37: 25-31.

Young, L. G. \& G. J. King, 1981. Reproductive performance of gilts bred on first versus third estrus. Journal of Animal Science 53: 19-25. 